\title{
Role of pelvimetry in active management of labour
}

\author{
D N JOYCE, F GIWA-OSAGIE, G W STEVENSON
}

British Medical fournal, 1975, 4, 505-507

\section{Summary}

All cases referred for pelvimetry in 1970-1 and all breech presentations referred for pelvimetry in 1972-4 were reviewed. Indications for pelvimetry fell into four main categories: high head in the antenatal clinic $(\mathbf{4 7 . 8} \%)$; high head in labour (13.9 $\%)$; breech presentation $(20.9 \%)$; and previous caesarean section $(14 \cdot 8 \%)$. In the first two categories pelvimetry rarely if ever influenced manage$m$ ?nt, and it should not be performed routinely. In breech presentation and cases of caesarean section pelvimetry seemed to be of value, but in the latter group it should be performed puerperally to avoid the known radiation hazard to the fetus. A fairly close correlation between obstetric conjugate and pelvic capacity was shown, which suggested that a 3400-g baby might pass through a pelvis of obstetric conjugate of $10 \mathrm{~cm}$ as a cephalic trial of labour, but would need an obstetric conjugate of $11.7 \mathrm{~cm}$ for safe vaginal breech delivery.

\section{Introduction}

The work of Stewart et $a l^{1-3}$ has clearly shown that a fetus irradiated in utero runs a greater risk in childhood of developing leukaemia or some other malignancy, a view endorsed by the International Commission on Radiological Protection. ${ }^{4}$ Calculations of modern dose levels by Reekie and Davidson ${ }^{5}$ suggest

King's College Hospital, London SE5

D N JOYCE, DM, MRCOG, lecturer in obstetrics (now consultant senior lecturer in obstetrics, South Mead Hospital, Bristol)

F GIWA-OSAGIE, BM, DRCOG, obstetric senior house officer

G W STEVENSON, MRCP, DMRD, senior radiological registrar (now consultant radiologist, Plymouth General Hospital, Devonport) that this risk is about 1 in 30000 for single obstetric abdomen or erect lateral pelvimetry films. The recognition of this radiation hazard has led many obstetric units to abandon full pelvimetry and to rely on a single erect lateral view in spite of a widespread belief that any single view of the pelvis has little value in predicting the capacity of the pelvis or the outcome of labour.

Active management of labour with amniotomy and oxytocin administration in slowly progressing labours has been widely adopted in this country after the pioneering work of O'Driscoll et $a l^{6}{ }^{7}$ and Philpott. ${ }^{8}$ Both groups found that active management led to a striking decrease in the apparent incidence of cephalopelvic disproportion, implying that much of what had previously been considered to be disproportion was, in fact, inefficient labour. Philpott's group made no attempt at antenatal assessment of pelvic capacity, adopting a trial of labour as the universal norm for managing possible disproportion.

In the light of these developments we felt it worthwhile to review the place and value of pelvimetry. At King's College Hospital a policy of active management of labour has been pursued since 1969. Low amniotomy is routinely performed when patients are established in labour and an intravenous oxytocin infusion used if good progress is not maintained as judged by partograms. Continuous fetal heart rate monitoring is used in all high risk cases, with fetal blood sampling when the heart rate is abnormal. Epidural anesthesia is also freely available and in 1974 was used for $33 \%$ of all deliveries.

\section{Patients and methods}

We studied all cases in which pelvimetry was performed during 1970 and 1971 and all the breech deliveries for which pelvimetry was performed during 1972, 1973, and 1974. We tried to answer two main questions: $(a)$ what influence did pelvimetry data have on the management of cases for which is was requested? (b) What predictive value has erect lateral pelvimetry in cephalic and breech presentation?

The $x$-ray films were remeasured without reference to the original report or the obstetric outcome until agreement was reached between two of us. The measurements recorded were the obstetric conjugate and the sacral angle. The obstetric conjugate was measured from the 
Mean obstetric conjugates and birthweights and method of delivery related to indication for pelvimetry in 1971-2

\begin{tabular}{|c|c|c|c|c|c|c|}
\hline \multirow{2}{*}{ Indication } & \multirow{2}{*}{ No $\left({ }_{0}^{\circ}\right)$ of cases* } & \multirow{2}{*}{$\begin{array}{l}\text { Mean obstetric } \\
\text { conjugate } \\
(\mathrm{cm})\end{array}$} & \multirow{2}{*}{$\begin{array}{c}\text { Mean } \\
\text { birthweight } \\
(\mathrm{g})\end{array}$} & \multicolumn{3}{|c|}{ Method of delivery $\left({ }^{\circ}\right.$ of patients $)$} \\
\hline & & & & Caesarean section & Forceps & Spontaneous \\
\hline $\begin{array}{l}\text { High head in antenatal clinic } \\
\text { High head in labour } \\
\text { Breech presentation } \\
\text { Previous caesarean section }\end{array}$ & $\begin{array}{l}55(47 \cdot 8) \\
16(13.9) \\
24(20.9) \\
17(14.8)\end{array}$ & $\begin{array}{l}10 \cdot 88 \\
10 \cdot 86 \\
12 \cdot 18 \\
11 \cdot 73\end{array}$ & $\begin{array}{l}3273 \\
3199 \\
3230 \\
3419\end{array}$ & $\begin{array}{l}27 \cdot 3 \\
37 \cdot 5 \\
16 \cdot 7 \\
29 \cdot 4\end{array}$ & $\begin{array}{l}34 \cdot 5 \\
25 \\
70 \cdot 8 \dagger \\
41 \cdot 2\end{array}$ & $\begin{array}{l}38 \cdot 2 \\
37 \cdot 5 \\
12 \cdot 5_{+}^{+} \\
29 \cdot 4^{+}\end{array}$ \\
\hline
\end{tabular}

*Percentages are of total group (115), though three patients examined for poor obstetric history have not been included in table.

inner edge of the pubic symphysis to the promontary or to the S1-S2 joint if this was nearer. The sacral angle was the angle between the true brim and a line from the sacral promontary to the most prominent part of the front of the first two sacral vertebrae. This angle broadly determines the capacity of the mid-cavity in relation to that of the brim.

\section{Results}

In 1970 and 1971 pelvimetry was performed in 115 cases. In two postpartum cases full pelvimetry was performed, but in the remainder only an erect lateral film was taken. The main indications, the mean pelvic measurements, fetal weights, and the methods of delivery in 112 patients are shown in the table. The remaining three patients were examined because of poor obstetric history.

In the 55 patients examined by $x$ rays because of high head in the antenatal clinic all went on to a trial of vaginal delivery, and careful scrutiny of the notes showed no case in which the management would have been any different if the $x$-ray films had not been taken. In four cases the pelvimetry film showed the fetal head to be engaged and in several more the head was clinically engaged before the onset of labour. It was more difficult to assess the influence of the $x$-ray films on the management of the 16 patients examined in labour because of a persisting high head. These patients underwent $x$-ray examination in the labour ward and five of the 16 films were of insufficient quality to allow measurement of pelvic diameters. In a few cases information of value was obtained-for example, in one case a false promontory was shown, which indicated that the fetal head had much further to go than was clinically apparent. Nevertheless, in most cases the rate of progress was the most important factor determining management.

In the breech presentation group pelvimetry seems generally to have been of value. The only two elective caesarean sections in the 1970-1 breech group were done on the only two patients with obstetric conjugates below $11 \mathrm{~cm}$. In the previous caesarean section group there were two elective sections, one in a patient with an obstetric conjugate of $9.9 \mathrm{~cm}$ and a previous failed trial of labour for a 4000-g baby, in whom the decision could have been made on clinical grounds, and the other in a patient with a small baby and a well shaped pelvis with an obstetric conjugate of $13.2 \mathrm{~cm}$, in whom the decision was obviously taken in spite of the pelvimetry. In only one of the previous caesarean section cases was pelvimetry performed in the puerperium.

The relation between obstetric conjugate, birthweight, and mode of delivery in those cases in 1970-1 in which a trial of labour was used is shown in fig 1 . All the caesarean sections for cephalic presentation are included here except one for placenta praevia and one for brow presentation. The indications for the others were failure to progress or fetal distress or a combination of these factors. The vaginal deliveries are concentrated in the upper left hand side of the diagram and lines have been drawn which empirically define zones where nil, $50^{\circ} \%$, and $90 \%$ of the women delivered vaginally.

From January 1970 to December 1974 there were 89 breech deliveries in patients who had had pelvimetry performed antenatally. There were five hydrocephalics which were excluded from further consideration. Of the remainder 56 delivered vaginally, 10 had elective caesarean sections, and 18 had caesarean sections during labour. The indications for the caesarean sections in labour were: failure to progress 11 cases, fetal distress four cases, and cord prolapse three cases. Apart from the hydrocephalics there was only one death in the total group. This was a 3820 -g fetus delivered as an assisted breech without undue difficulty through a $12 \cdot 2 \mathrm{~cm}$ obstetric conjugate pelvis. The baby collapsed and died two days after delivery and necropsy showed a subarachnoid haemorrhage. There was no record of any significant trauma in any other case.

The relation between birthweight and obstetric conjugate and method of delivery for these breech deliveries is shown in fig 2 . Failed vaginal delivery included all the caesarean sections in labour except

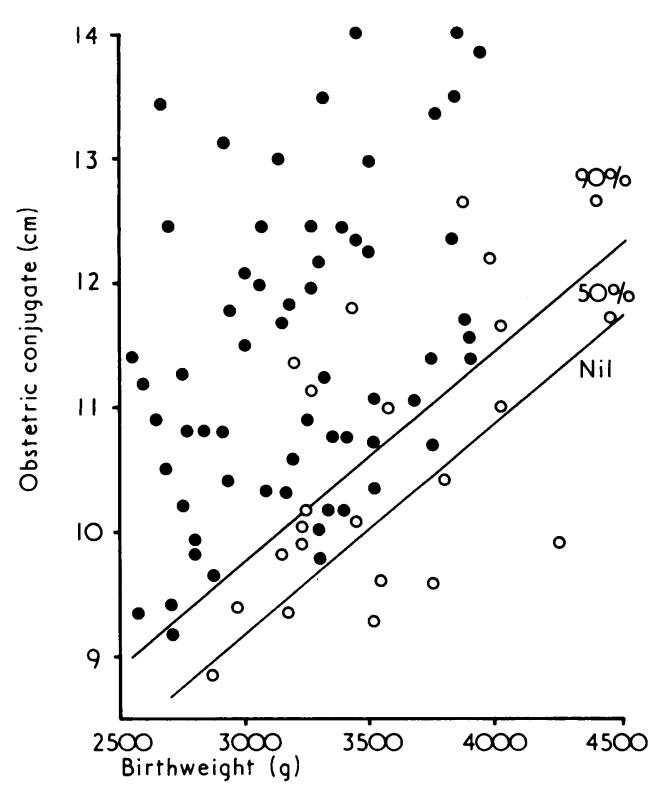

FIG 1-Relation between obstetric conjugate, birth weight, and outcome of labour in trial of labour with cephalic presentation 1970-1. = Vaginal delivery. $0=$ Caesarean section for failed trial of labour.

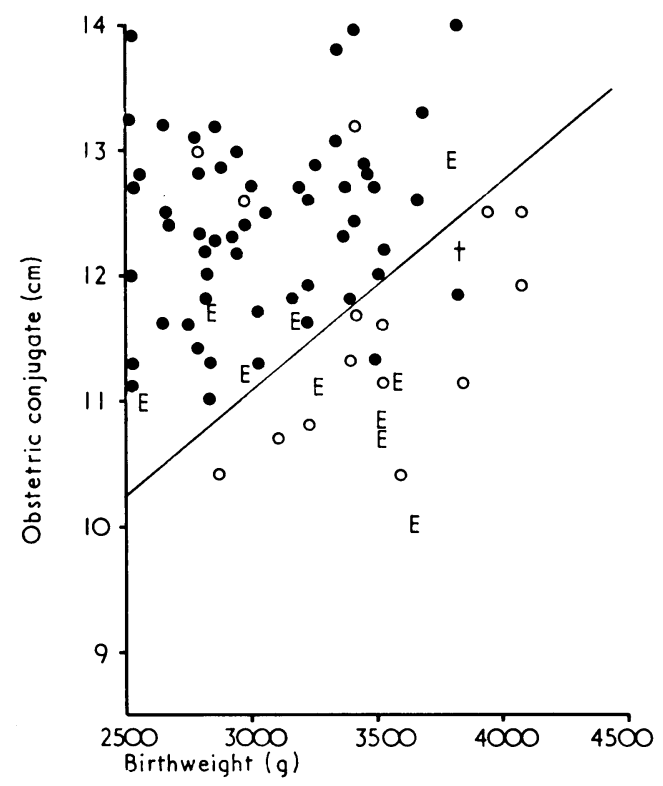

FIG 2-Relation between obstetric conjugate, birthweight, and outcome of labour for breech presentation 1970-4. - Vaginal delivery. $O=$ Failed vaginal delivery. $E=$ Elective caesarean section. $\dagger=$ Neonatal death after vaginal delivery.

the three for cord prolapse. A line parallel to those in fig 1 can be drawn which separates most of the failed vaginal deliveries from the successful vaginal deliveries. This line is the equivalent of $1.8 \mathrm{~cm}$ of 
obstetric conjugate higher than the bottom line of the trial of labour chart and $1.3 \mathrm{~cm}$ higher than the top line. Apart from elective caesarean section and cord prolapse the indications for the ceasarean sections which fell above this line were fetal distress (1) and failure to progress (2). Indications for those below the line were fetal distress (3) and failure to progress (9). There was one successful vaginal delivery which fell off the chart and below the line. This was a Cushingoid prediabetic baby weighing $4585 \mathrm{~g}$ who was delivered through a pelvis with an obstetric conjugate of $12 \cdot 1 \mathrm{~cm}$. This baby had a head circumferance of only $34 \mathrm{~cm}$, a measurement which is the mean for a weight of $3150 \mathrm{~kg}$. Such a birthweight would have fallen well above the line.

We found no significant correlation between sacral angle and outcome of labour in either cephalic or breech presentations.

\section{Discussion}

We were surprised to find such a clear correlation for both cephalic and breech presentation between obstetric conjugate and the size of fetus that could deliver vaginally. The active management of labour has probably eliminated much of the uncertainty in labours associated with poor uterine action, in which disproportion was often assumed to be present. It is also possible that our obstetric population has more uniformity of pelvic shape than was the case 20 or 30 years ago in the "golden age of pelvimetry," when some women had pelves distorted by rickets. The higher cut-off line in breech presentation is in keeping with traditional obstetric teaching, and with the Perinatal Mortality Survey findings of minimal breech mortality in birthweight groups below $3175 \mathrm{~g}(7 \mathrm{lb})$. Our data suggest that for the average breech at term (weight $3400 \mathrm{~g}$ ) a minimum obstetric conjugate of $11.7 \mathrm{~cm}$ would be necessary for safe vaginal delivery, and for the average breech at 38 weeks (weight $3200 \mathrm{~g}$ ) an obstetric conjugate of $11.4 \mathrm{~cm}$ would be necessary.

The value of pelvimetry in predicting the outcome of labour is limited by the difficulties of assessing fetal weight, though there is a fairly close correlation between fetal weight and biparietal diameter measured by ultrasound. From the data of Campbell ${ }^{9}$ biparietal diameters corresponding to $2500,3000,3500$, and $4000 \mathrm{~g}$ are $88,94,101$, and $108 \mathrm{~mm}$ respectively.

Despite the reasonable correlation with outcome antenatal pelvimetry is rarely justified except in breech presentation. With a breech the size of pelvis that is needed for an average-sized baby is beyond the reach of accurate clinical assessment. The known risks to the fetus of difficult breech delivery easily outweigh the radiation hazard. On the other hand, with a cephalic presentation an average-sized baby can be expected to pass through a pelvis which is detectably small on clinical assessment. Furthermore, there is no evidence that a failed trial of labour entails any significant risk to the fetus. In a primigravida an elective caesarean section for disproportion is only likely to be indicated when the pelvis is distorted by bony disease or fracture. In patients with a previous caesarean section or poor obstetric history pelvimetry may influence the management of the case but should generally be performed in the puerperiun. rather than during the next pregnancy. With twins there is $\mathrm{n}$, appreciably greater risk for breech presentations, as the babies tend to be both premature and small for dates. Pelvimetry for twins is only likely to be of value in patients with a clinically suspected contracted pelvis.

In summary, routine pelvimetry should be performed only in the following cases: (a) antenatally, for singleton breech presentations in primigravid and multigravid patients; (b) postpartum, after a caesarean section, difficult forceps delivery, or perinatal death, when vaginal delivery might be considered in a subsequent pregnancy; $(c)$ before pregnancy, after the healing of a fractured pelvis or at some suitable point in the management of other relevant orthopaedic disorders.

\section{References}

1 Stewart, A M, et al, Lancet, 1956, 2, 447.

2 Stewart, A M, Webb, J W, and Hewitt, D, British Medical fournal, 1958, $1,1495$.

${ }^{3}$ Stewart, A M, and Kneale, G W, Lancet, 1968, 1, 104.

+ International Commission on Radiological Protection, Health Physics, 1966, 12, 291.

${ }^{5}$ Reekie, D, and Davidson, J K, British Fournal of Radiology, 1967, 40, 849.

${ }^{6}$ O'Driscoll, K, Jackson, R J A, and Gallagher, J T, British Medical fournal, $1969,2,477$.

' O'Driscoll, K, Jackson, R J A, and Gallagher, J T, fournal of Obstetrics and Gynaecology of the British Commonwealth, 1970, 77, 385.

* Philpott, R H, British Medical fournal, 1972, 4, 163.

${ }^{9}$ Campbell, S, Clinics in Obstetrics and Gynaecology, 1974, 1, 55.
How does one effectively immunise a child suffering from atopic dermatitis (infantile eczema) against smallpox in the first two years of life if the child must leave Britain to return to his native country-an area highly endemic for smallpox?

If children with eczema need vaccination before travelling to a country where smallpox is endemic, it should be immediately preceded by vaccinia immune globulin $\left(0.3 \mathrm{ml} / \mathrm{kg}\right.$ intramuscularly). ${ }^{1}$ There has been no controlled trial of this procedure, but cases of eczema vaccinatum occurring subsequently are reported to be "extremely mild." Vaccinia immune globulin is obtainable in Britain from the Public Health Laboratory Service and in the USA from the Center for Disease Control, Atlanta, Georgia.

' Lane, J M, fournal of the American Medical Association, 1974, 227, 448.

What is the incidence of vaccination encephalitis in children and is this severe reaction as likely' to recur in susceptible individuals if vaccination is left until later in life? What regimen reduces this risk to a minimum while providing maximum protection?

A national survey in the USA ${ }^{1}$ showed that the incidence of encephalitis after primary vaccination was 0.7 per 1000000 under the age of 1 year, 0.2 between 1 and 4 years, and only one case after 10 years. No cases occurred after revaccination. Although other series have shown differences between countries and presumably the various preparations of vaccinia virus," it was generally agreed in Britain, where smallpox is not endemic, that the safest age to administer the vaccine was in the second year of life. In recent years, however, with the more effective control of smallpox worldwide the relative risks of the complications of vaccination have appeared to exceed that of the chance of dying from the disease itself in non-endemic countries, and now Britain along with the USA no longer recommends routine vaccination. Travellers to countries where smallpox is endemic and certain higher risk groups in this country-such as doctors, nurses, etc-still need protection. In endemic countries, vaccination should not be delayed until the second year and some authorities recommend it within the first few weeks of life.

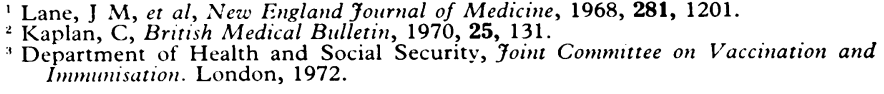

In women urethritis often seems to be precipitated by coitus. Is there any evidence that it is more likely after unstimulated coitus, when the urethra is not cushioned by the distension of nearby erectile tissue?

Urethritis does occur in some women after coitus and occurs most often after the first intercourse in virgins. The so-called "honeymoon cystitis" is also well known but this may be related to frequency of coitus. It is generally assumed that lower renal tract infections thus caused are traumatic. In some women the attacks are chronic and frequent and long-term antibiotic treatment may be required. There does not seem, however, to be any evidence that urethritis occurs more often after unstimulated than stimulated coitus. 